\title{
Analysis on Politics Teachers' Professional Quality Evaluation Methodology
}

\author{
Yexia Sun \\ School of Marxism, Northeast Normal University, People Street No.5268, Nanguan District, \\ Changchun, Jilin Province, China \\ sunyexia@126.com
}

Keywords: Politics teachers; Evaluation subject; Evaluation system; Evaluation method

\begin{abstract}
This article confirms the guiding ideology, objective and subject of our country's politics teachers' professional quality evaluation, and uses it as a basis for further analysis on some of the major methods of politics teachers' professional quality evaluation. According to China's politics teachers' characteristics, the politics teachers' professional quality evaluation system is established.

Professional teachers' quality evaluations are more in China, but the evaluation still relatively small just for the politics teachers' evaluation. This article will be devoted to the analysis of evaluation methods for politics teachers, and try to establish professional evaluation index system of politics teachers.
\end{abstract}

\section{Build Guidelines and Objectives of Politics Teachers' Professional Quality Evaluation Guideline of Evaluation Index System}

Based on respecting the evaluation regularity, the party and the country's spirit of politics construction as a guide, adhering to the combination of self-evaluation and other-evaluation, establishing and improving the evaluation mechanism of teachers, individuals, peers, experts and students to participate in jointly, focusing to improve teachers' professional level as the purpose to make diagnostic function, orientation function, intensify function, self-education function and research function [1].

Objective of Evaluation Index System. The aim of the politics teachers' professional quality evaluation is through an objective, fair, timely and reliable assessment of the height of the teachers' thought, teaching quality and effectiveness, research work quantity and quality, and the attainment of teachers themselves to seek politics teachers' strengths and weaknesses, providing specific and accurate feedback information in order to promote the development of their own and teaching and scientific research level. By teachers' assessment and identifying the effectiveness of teaching behavior, it can help teachers to understand, develop and improve themselves, further to improve their professionalism, and achieve the purpose of teaching.

\section{Politics Teachers Professional Quality Evaluation Subject}

Politics teachers professional quality evaluation subject generally includes experts, peers, teachers themselves, students, society, etc. In the evaluation activities, according to the different purposes and focuses of the evaluation, the different evaluation subjects should be given with various weight distributions.

Experts' Evaluation. Experts evaluate politics teachers' professional quality from the education regularity, which has a greater guiding significance for teachers. But experts themselves have a strong hint of authority, the premise to ensure the real guiding importance of experts' evaluation is to guarantee the objectivity and scientificalness of their evaluation.

Peers' Evaluation. Peers often evaluate teachers from teaching and research group and the institute, because these teachers know well each other, and they can assess more objectively for their professional ability and work performance, especially in the identifying politics teachers' professional literacy level, so peers' evaluation can play a very important role.

Teachers' Self-Evaluation. Teacher's self-evaluation is to evaluate themselves based on their 
real situation according to certain criteria. Self-evaluation is a nonnegligible important evaluation subject, it not only makes politics teachers identify their strengths and weaknesses, but also stimulates the teachers' self-awareness, generates self-education and self-motivation effects. However, when the comments link to personal interests, the teacher's self-evaluation will be prone to go awry [2].

Students' Evaluation. Teachers and students coexist for the longest duration, the students have the most direct experience for their teachers, so their assessments can reflect the politics teachers' professional qualities to some extent. Students can directly evaluate teachers' teaching performance by scoring, opening forums, questionnaires, asking for opinions, etc.

Social Evaluation. Social evaluation is mainly reflected in public opinion evaluation, and it not evaluates directly for politics teachers' various qualities, which specific university, which province or different titles of teachers, it is only applicable to politics teachers' overall quality. Although social evaluation is not mandatory with a generalization phenomenon, there are the functions of reminding, promotion and encouragement for politics teachers [3].

Evaluation degree is different for evaluating the various professional qualities' subjects. Peers and experts are more profound on occupational ideological literacy, vocational theoretical attainment and professional ethic evaluation, but experts and peers without in-depth classroom cannot comprehensively evaluate teachers' professional practice ability literacy and expansibility attainment. Self-evaluation is an evaluation of teachers' all aspects of self-performed qualities, and this evaluation is more comprehensive, while it's result is more subjective on account of their own evaluation, and the participators may artificially raise a certain professional quality evaluation on the basis of the evaluation result, and it even reduces a certain professional quality evaluation, so there is inevitable one-sidedness. It is difficult to properly evaluate abstract professional thought quality, professional theoretical attainment and professional ethic although students have most speaking rights for teachers' professional practice ability literacy and developmental literacy. Specifically, politics teachers not only should impart knowledge, bur also is the indoctrinator of thinking on teaching the course, so politics teachers are required with high professional ethics. Moral accomplishment is a more abstract quality, so the moral quality evaluation is mainly through method of self-evaluation. Politics teachers professional practice capacity mainly refers to the literacy levels of teachers' various practical skills required by the station primarily by experts, peers and self-evaluation evaluation methods, which is carried out by questionnaires. Developmental literacy includes career information literacy, professional psychological quality aesthetic accomplishment, which is primarily surveyed by questionnaires to students and student's class observations.

\section{The Main Methods of Politics Teachers' Professional Quality Evaluation}

There are many politics teachers' professional quality evaluation methods, mainly including qualitative analysis method and quantitative analysis method. According to the characteristics of politics teachers' professional quality evaluation, there are the following four kinds of professional quality evaluation methods.

Research Method. Research method is a scientific understanding method and important research method of Marxism. It requires the researchers fully grasp the first-hand materials about the history, current situation and development trend of study object as much as possible on the basis of dialectical materialism and historical materialism, and comprehensively and thoroughly study these materials to obtain regular awareness and draw the right conclusions with objective reality [4].

Peer Review Method. English expression of this method is "Peer Review". "Peer" refers to persons with the same qualifications and capacities, "Review" is accountability-oriented or circumspect check or inspection. Peer review refers to a method consists of experts working in this field or close to the field to evaluate a study work's academic level or importance. In China, peer review method is mainly used in scientific research assessment. Research is a small accomplishment politics teachers need to be equipped with, and the same method can also be used to evaluate politics teachers' professional qualities. Specifically, peer review method can be divided 
into two kinds of peer expert review method and expert scoring method [5].

Multi-Index Comprehensive Evaluation Method. Multi - index comprehensive evaluation method is the method that uses multiple indicators to evaluate a plurality of participating units, also known as multi-variable comprehensive evaluation method or comprehensive evaluation method. Its basic idea is to evaluate through transferring multiple indicators into a index that reflects the general situation. This method can be applied into politics teachers' professional quality level, different nations' economic strength, various regions' social development level [6].

Weighted comprehensive evaluation can be used in professional quality evaluation: First, the evaluation factors and evaluation index system corresponding to each element should be determined. Each evaluation point has a number of indicators (for example, 5 - 10 indicators), each index score will be confirmed according to politics teachers' specific performance. Secondly, the weight of each evaluation factor will be ascertained in line accordance with the designer's value and target. Finally, weighted summation obtains integrated value, and the value is converted to the corresponding level.

The evaluation steps of multi-index comprehensive evaluation method:

First, comprehensive evaluation index system should be determined, which is the basis and foundation of comprehensive evaluation.

Second, data should be collected, and to process index data in different measurement units.

Third, the weights of each index in index system should be confirmed to ensure the scientificalness of evaluation.

Fourth, comprehensive index or comprehensive evaluation score should be calculated after aggregating the post-treatment progress indicators.

Fifth, ranking the participating units according to the evaluation indexes or scores, and than have the conclusion.

The Evaluation Index System. The evaluation index is determined according to a certain evaluation objective, and reflect the specific evaluation item of objects' certain essential characteristics. Indicator is specific and measurable, is the target of behavior and operation, and can be definitely concluded through actual observation of the object [7]. Evaluation index system is a aggregation of systematized, close-ralated a cluster of indicators and specific indicators reflect the overall evaluation object, and which is an organic entirety formed by the different levels of evaluation objects' logical structures. It is a gauge system that measures politics teachers' professional quality development level or condition. Evaluation index can only reflect and evaluate one aspect or several aspects of the evaluation object and target, while the evaluation index system can more fully reflect the evaluation object and target [8].

According to the foregoing related demarcation, 4 first level indicators, 16 secondary indicators, 55 three level indicators are established in the construction of politics teachers' professional quality index system, specifically as follows:

Table 1 Politics teachers professional quality indicators grading schedules

\begin{tabular}{|c|c|c|c|}
\hline First level indicators & Secondary indicators & Three level indicators & Weights \\
\hline \multirow{13}{*}{ Thought qualities } & \multirow{4}{*}{$\begin{array}{l}\text { Professional } \\
\text { awareness quality }\end{array}$} & Party spirit consciousness & \\
\hline & & Problem awareness & \\
\hline & & Discipline awareness & \\
\hline & & Science awareness & \\
\hline & \multirow{3}{*}{$\begin{array}{l}\text { Professional spirit } \\
\text { quality }\end{array}$} & Professionalism spirit & \\
\hline & & Professional enthusiasm spirit & \\
\hline & & Innovative spirit & \\
\hline & \multirow{3}{*}{$\begin{array}{l}\text { Professional ideal } \\
\text { quality }\end{array}$} & Political ideals of communism & \\
\hline & & Social ideal to achieve Chinese dream & \\
\hline & & Cultivating people's ideal of education & \\
\hline & \multirow{3}{*}{$\begin{array}{l}\text { Professional idea } \\
\text { quality }\end{array}$} & Respecting the philosophy of education & \\
\hline & & Leading society's practice philosophy & \\
\hline & & Time-oriented academic philosophy & \\
\hline
\end{tabular}


Table 1, cont.

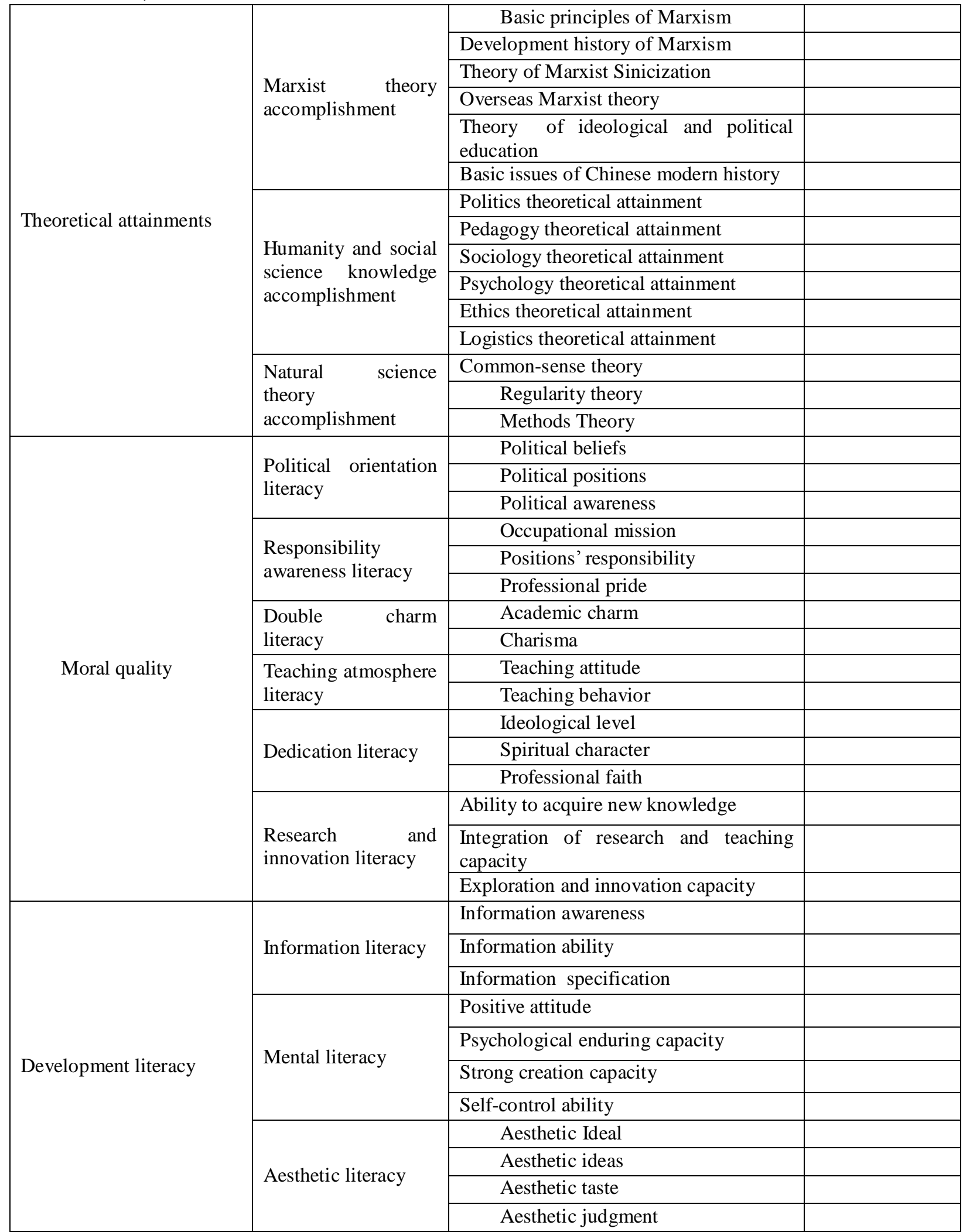

Various factors are important in evaluation of teachers professional quality, but with different importance degree, which is the weight distribution problem. Because of the large differences of schools at all levels, teachers evaluation purposes will be different, so uniform weight coefficients can not be established. The following methods of weight distribution are recommended:

(a). Formula method. $E(O)=\sum_{i} w_{i} E\left(o_{i}\right) . E(O)$ shows the evaluation result of the evaluation 
objective $O, E\left(o_{i}\right)$ is evaluation result of $O$ 's sub-goal, $w_{i}$ expresses the weight of sub-target $o_{i}$ occupied in the upper target. Politics teachers professional general evaluation level is a weighted average of first level professionalism weight and evaluation result. The aggregate level of first level professionalism is a weighted average of secondary professionalism' weight and evaluation result, and so on [9].

(b) Ranking method. There are five categories in determining the specific evaluation level, more than 90 points for the excellent, 80-89 for the good, 70-79 for the middling, 60--69 for the qualified, under 60 for the inferior. Different schools can be defined depending on the various objectives and requirements. This evaluation method can also be defined indistinctly. In the evaluation of three level quality, which is direct assessed by excellent, good, middling, qualified and inferior. Secondary level quality is ensured by particular cases, and first level quality is evaluated by the secondary level quality, then to finalize the overall professionalism. This demarcation method has a more stronger implementation, but the evaluation result has a certain deviation on account that quality levels determined each time are the average quality level [10].

\section{References}

[1] Hou Yujuan, Deng Chunhui, The Particularity of Politics Teachers' Teaching Ability Evaluation in Colleges and Universities---- Ideological and Political Course Teaching Work Particularity as the Source, Journal of Taiyuan city Vocational and Technical College, 2013 (6).

[2] Zhao Xue, Status Quo of New Construction University Politics Teachers' Individual Professional Development and Evaluation, Science and Technology Information, 2015 (3).

[3] Wang Jing, University Teacher Evaluation Research Overview, Education Article Collects, 2015 (3).

[4] Liu Ye, Han Ying, Liu Qiang, Study of New Time Politics Teachers in University Performance Evaluation Methods, Reform and Opening up, 2015 (7).

[5] Yan Shuquan, A Useful Exploration of the politics teachers evaluation system---- Ideological and Political Theory Course Teachers' Competency Study Review, Northern Economy and Trade, 2012 (3).

[6] Xiao Guoxiang, Higher Vocational Ideological and Political Theory Course Assessment System Design and Practice Nurtured on the Basis of Professional Quality----Exampled as Ideological and Moral Cultivation and Elementary Law Course, New Curriculum Study, 2015 (9).

[7] Hou Yujuan, Deng Chunhui, On the Improvement of University Politics Teachers' Teaching Basic Skills Evaluation System, Tai'an Education College Dai Zong Journal, 2011 (12).

[8] Li Ying, Study of College Politics Teachers Teaching Performance Evaluation System Design, Enterprises Herald, 2015 (9).

[9] Wang Lixia, Politics Teachers Professional Quality in New Situation, Cultural Journal, 2016 (7).

[10] Zhong Xuemin, On Politics Teachers Professional Quality in New Time, Realistic, 2014 (6). 